International Journal of Food Science, Nutrition and Dietetics (IJFS)

ISSN 2326-3350

\title{
Chromium Status, Assessed By Hair Analysis, In Women With Type 2 Diabetes Mellitus
}

C. L. Magson ${ }^{1}$, R. Knight ${ }^{2}$, S. J Haswell², E. A. Masson ${ }^{3}$, S.W. Lindow ${ }^{4 *}$

Research Article

${ }^{1}$ Dept Paediatrics, Hull Royal Infirmary. Hull. HU3 2JZ. UK.

${ }^{2}$ Department of Chemistry, University of Hull, UK.

${ }^{3}$ Dept Endocrinology and Diabetes, Hull Royal Infirmary, Hull, HU3 2JZ. UK.

${ }^{4}$ Hull York Medical School, Hull Royal Infirmary, Hull, HU3 2JZ. UK.

\section{Abstract}

Aims: To assess chromium status using human scalp hair in females with Type 2 Diabetes and a control group of women.

Methods: The participants were two groups of women aged between 35 and 70: 35 women with Type II diabetes (study group) and 30 women with no history of diabetes (control group). Samples of scalp hair were collected and the chromium content analysed by inductively coupled plasma mass spectrometry.

Results: No significant difference was found between the levels of chromium in the hair samples of the women in each group. Chromium was found to be higher in the diabetic group than the control group. (0.59 Vs $0.52 \mu \mathrm{g} / \mathrm{g}$ ). The two groups had a similar weekly diet, apart from alcohol, chocolate, cream and milk; significantly more controls consumed these products.

Conclusion: There was no evidence of chromium deficiency in women with type 2 diabetes.

Key Words: Hair Analysis; Chromium; Diabetes.

\section{*Corresponding Author:}

S.W. Lindow

Hull Royal Infirmary, Anlaby Road, Hull, UK.

Tel: +44 1482 382769; Fax: +44 1482382781

E-mail: stephen.lindow@hey.nhs.uk

Received: November 20,2013

Accepted: November 30, 2013

Published: December 02, 2013

Citation: S.W. Lindow et al (2013) Chromium Status, Assessed By Hair Analysis, in Women with Type 2 Diabetes Mellitus. Int J Food Sci Nutr Diet. 2(8), 81-84. doi: http://dx.doi.org/10.19070/2326-3350-1300015

Copyright: S.W. Lindow. ${ }^{\circledR} 2013$ This is an open-access article distributed under the terms of the Creative Commons Attribution License, which permits unrestricted use, distribution and reproduction in any medium, provided the original author and source are credited.

\section{Introduction}

In the 1970's chromium was discovered to be an important trace element, required for maintaining normal glucose metabolism. This was discovered by chance when a patient developed elevated blood glucose after being administered long-term total parental nutrition, which did not contain chromium [1]. A small amount of chromium was administered and the blood glucose fell to within the normal range. A review of studies by Anderson in 1998 concluded that chromium supplementation improved levels of blood glucose, insulin, cholesterol and haemoglobin A1c in people with varying degrees of glucose intolerance [2]. Its physiological role appears to be that of a co-factor, potentiating the action of insulin in cellular glucose uptake. Chromium is primarily obtained from black pepper, brewer's yeast, mushrooms, prunes, raisins, nuts, asparagus, milk, beer and wine [3].

This is the first study to analyse not only the chromium status of type 2 diabetic women compared to non-diabetics, but also to look closely at any differences in the dietary intake between the two groups.

\section{Patients and Methods}

The local ethics and research committee approved this study. The women also gave their consent to be included in the investigation. Chromium status was tested in 65 caucasian women divided into two groups. Group 1 was made up of 30 women who did not have diabetes. These women were mainly recruited from hospital and university staff and women accompanying clinic patients. Group 2 consisted of 35 women between the ages of 35 and 70 previously diagnosed with type 2 diabetes, attending the routine Diabetic Clinic over a 2 -week period.

The hospital record for each diabetic woman was reviewed to assess suitability. Women who had type 1 diabetes and women whose diabetes was secondary to other pathology such as pancreatic disease and use of steroids were excluded. This study concentrated on women only, as a previous study had shown significant differences between chromium levels of the two sexes [4] and hair samples may not be consistently available from middle aged men.

Data on the use of hair care products and dietary intake was collected via a questionnaire completed during an interview with the researcher (CLM). Information regarding their diabetes was obtained from the woman's medical records. 
Analysis of Hair Specimens by Inductively Coupled Plasma Mass Spectrometer (ICPMS)

The hair sample was collected using scissors, taking a sample of the soft hair from the back of the scalp, just above the hairline. The hair sample was then placed in a plain plastic bag. The hair was weighed and placed in a Teflon Advanced Composite Vessel (ACV) with $5 \mathrm{~mL}$ nitric acid (Romil SpA grade) and left loosely covered overnight. The ACV was then sealed and placed, with up to 11 other ACVs, in a microwave oven (CEM MDS 81D) and heated for 10 minutes at a maximum of 100 psi. After cooling, the vessels were opened and their contents diluted up to $25 \mathrm{ml}$ with water (Elga UHQ grade).

Fifteen samples were too small to be placed directly into the ACV and were placed with $1 \mathrm{~mL}$ of nitric acid into $3 \mathrm{~mL}$ and $7 \mathrm{~mL}$ microdigestion vessels. One microdigestion vessel was then placed in an ACV with $10 \mathrm{~mL}$ of water and a spacer. The ACV was then sealed and heated as previously described. After cooling, the contents of the microdigestion vessels were diluted with water up to $5 \mathrm{~mL}$. The two methods, therefore, used the same acid concentration $(20 \%)$, thus making the results using the two methods comparable. The analysis of elements followed standard procedures outlined in similar studies in our laboratory [4].
The metals, including chromium, were calibrated up to $5 \mu \mathrm{g} / \mathrm{g}$ (ppb) with standards containing 0,1,2, 3, 4 and 5 ppb metals, which gave linear calibrations. Analysis was performed using mass spectrometry (Thermo Elemental Plasma Quad II), with a detection limit of $0.006 \mu \mathrm{g} / \mathrm{g}$ for chromium.

Statistical analysis was performed by SPSS using parametric tests for numerical and non-parametric tests for ordinal data as appropriate.

\section{Results}

The average time since diagnosis of type 2 diabetes was 6.8 years. $1(4 \%)$ woman is treated by diet only, $14(40 \%)$ women were treated by oral medication and the remaining 20 (56\%) were treated using insulin.

The diabetic women were significantly older (Table 1). The two groups were comparable with respect to their height, although the diabetic women had a greater mean weight and thus a greater mean BMI.

The two groups had very similar weekly dietary intake of most foodstuffs, apart from alcohol, chocolate, cream and milk; significantly more controls consumed these products. (Table 2 and 3).

Table 1: General characteristics in the two groups of patients studied. Values are given as mean (SD).

\begin{tabular}{|l|l|l|l|l|}
\hline Characteristics & Control $\boldsymbol{n}=\mathbf{3 0}$ & Diabetics $\boldsymbol{n}=\mathbf{3 5}$ & $\mathbf{T}$ & $\mathbf{P}$ \\
\hline Age (years) & $52.50(6.24)$ & $57.51(8.84)$ & 2.668 & $.01($ CI 1.7-8.8) \\
\hline Height $\mathbf{( c m )}$ & $165.5(8.98)$ & $161.1(8.28)$ & -1.965 & NS \\
\hline Weight $\mathbf{( k g )}$ & $73.32(15.07)$ & $86.6(17.57)$ & 3.114 & 0.003 (CI 4.7-21.8) \\
\hline BMI $\left.\mathbf{( k g} / \mathbf{m}^{2}\right)$ & 26.8 & 33.4 & & \\
\hline
\end{tabular}

Table 2: Consumption of food and drink (Chi-square Analysis). Values are given as n (\%).

\begin{tabular}{|l|l|l|l|}
\hline Food and Drink & Control $\boldsymbol{n}=\mathbf{3 0}$ & Diabetics $\boldsymbol{n}=\mathbf{3 5}$ & $\boldsymbol{P}$ \\
\hline Alcohol & $23(77)$ & $6(20)$ & .000 \\
\hline Smoking & $3(10)$ & $6(18)$ & NS \\
\hline Vitamins & $14(47)$ & $7(20)$ & .022 \\
\hline Bread & $30(100)$ & $35(100)$ & NS \\
\hline Cereals & $28(93)$ & $29(83)$ & NS \\
\hline Cheese & $28(93)$ & $28(80)$ & NS \\
\hline Chocolate & $23(77)$ & $11(31)$ & .000 \\
\hline Cream & $10(33)$ & $4(11)$ & .032 \\
\hline Fruit & $28(93)$ & $35(100)$ & NS \\
\hline Nuts & $8(27)$ & $4(11)$ & NS \\
\hline Potato & $30(100)$ & $32(91)$ & NS \\
\hline Peas or beans & $28(93)$ & $34(97)$ & NS \\
\hline Seafood & $22(63)$ & $20(58)$ & NS \\
\hline Snacks & $21(70)$ & $24(69)$ & NS \\
\hline Red meat & $28(93)$ & $32(91)$ & NS \\
\hline Liver or kidney & $16(53)$ & $14(40)$ & NS \\
\hline Chicken or turkey & $29(97)$ & $32(91)$ & NS \\
\hline Milk & $30(100)$ & $29(83)$ & .000 \\
\hline Tea / Coffee & $29(97)$ & $35(100)$ & NS \\
\hline
\end{tabular}


Table 3: Intake of food and drink in the women who consumed that food/drink (Mann Whitney U Test). Values are given as mean (SD)

\begin{tabular}{|l|l|l|l|}
\hline Amount consumed/week & Control $\boldsymbol{n}=\mathbf{3 0}$ & Diabetics $\boldsymbol{n}=\mathbf{3 5}$ & $\boldsymbol{P}$ \\
\hline Alcohol (units) & $7.0(4.9)$ & $4.3(3.1)$ & NS \\
\hline Smoking (cigs/day) & $18.3(2.9)$ & $14.2(7.4)$ & NS \\
\hline Bread (slices) & $19.1(11.1)$ & $23.9(10.4)$ & 0.021 \\
\hline Cereals (bowls) & $5.8(1.8)$ & $4.4(2.5)$ & NS \\
\hline Cheese (helpings) & $2.8(1.8)$ & $2.2(1.7)$ & NS \\
\hline Chocolate (bars) & $1.5(1.0)$ & $1.7(1.2)$ & NS \\
\hline Fruit (pieces/day) & $2.8(1.0)$ & $2.3(1.3)$ & 0.034 \\
\hline Nuts (ounces) & $3.2(1.7)$ & $2.5(2.4)$ & NS \\
\hline Peas or beans (helpings) & $3.3(1.8)$ & $3.1(1.7)$ & NS \\
\hline Potato (helpings) & $5.0(1.9)$ & $4.2(2.0)$ & NS \\
\hline Seafood (helpings) & $2.0(1.5)$ & $1.7(1.0)$ & NS \\
\hline Snacks & $3.5(2.6)$ & $3.0(3.3)$ & NS \\
\hline Red meat (portions) & $4.6(2.6)$ & $3.4(1.9)$ & NS \\
\hline Liver or kidney (portions) & $0.8(0.6)$ & $0.8(0.6)$ & NS \\
\hline Chicken or turkey (portions) & $2.6(1.3)$ & $1.9(0.8)$ & 0.011 \\
\hline Milk (pints) & $3.5(2.2)$ & $3.6(2.0)$ & NS \\
\hline Tea / Coffee (cups/day) & $5.7(2.0)$ & $4.8(2.0)$ & NS \\
\hline Milk & $30(100)$ & $29(83)$ & .000 \\
\hline Tea / Coffee & $29(97)$ & $35(100)$ & NS \\
\hline
\end{tabular}

Table 4: General characteristics in the two groups of patients studied. Values are given as mean (SD).

\begin{tabular}{|l|l|l|l|}
\hline Hair Treatment & Control $\boldsymbol{n}=\mathbf{3 0}$ & Diabetics $\boldsymbol{n}=\mathbf{3 5}$ & $\mathbf{P}$ \\
\hline Hair colouring & $24(80)$ & $17(49)$ & .009 \\
\hline Hair Spray and mousse & $20(67)$ & $18(51)$ & NS \\
\hline Permanent Wave & $5(17)$ & $11(31)$ & NS \\
\hline Bleaching & $11(37)$ & $7(20)$ & NS \\
\hline
\end{tabular}

The use of most hair care products was similar for both the control and the diabetic groups (Table 4), but the use of a hair colourant was significantly greater in the control group (80\% Vs 49\%). If chromium levels in all women are analysed with respect to hair colouring status, there is no difference in the level of chromium in women with coloured hair compared to those without (Mann Whitney U test $=0.799-$ Not Significant).

The hair sample size ranged from $0.003 \mathrm{~g}$ to $0.1 \mathrm{~g}$. Chromium was found to be not significantly different in the diabetic group than the control group. (mean chromium $0.59 \mathrm{Vs} 0.52 \mu \mathrm{g} / \mathrm{g}$ ) (Mann
Whitney $\mathrm{U}$ test $\mathrm{p}=\mathrm{NS}$ ) (table 1$)$

\section{Discussion}

Chromium levels in hair samples were analysed to assess the chronic chromium status in 2 groups of woman. Hair has previously been shown, to be an excellent material for assessing chromium $[5,6,7]$. Measurements of chromium status using hair samples have previously been shown to correlate well with serum levels [5].

The use of hair spray, mousse, permanent wave and bleaching

Table 5: Hair chromium levels ( $\mu \mathrm{g} / \mathrm{g})$. (Mann-Whitney U test - No significant differences)

\begin{tabular}{|l|l|l|}
\hline & Control $\boldsymbol{n}=\mathbf{3 0}$ & Diabetics $\boldsymbol{n}=\mathbf{3 5}$ \\
\hline Mean & 0.524 & 0.591 \\
\hline Median & 0.515 & 0.586 \\
\hline Standard Deviation & 0.361 & 0.411 \\
\hline Minimum & 0.050 & 0.019 \\
\hline Maximum & 1.565 & 1.688 \\
\hline
\end{tabular}


between the two groups was not significant. The use of hair colouring products is significantly different, although this finding may not influence the results substantially, as hair was taken from the soft hair at the top of the neck, which grows rapidly and is often not reached by hair colouring products. Women with dyed hair did not differ in their chromium levels from women without dyed hair

After comparing the general features of the two groups, it was found that the diabetic group were significantly older (52.5 years versus 57.5 years) (table 1). Chromium levels have been shown in previous studies to decrease with age [5]. It should, however, be noted that the chromium levels in the small age range of women used in this study would not decrease enough to be a possible cause of error. This is further emphasised as, if chromium levels decreased with age, then the mean level of chromium should have been correspondingly lower in the diabetics, who were older, but it was actually slightly higher.

The two groups are similar in height, but the mean weights and therefore BMI's of the diabetics was greater (Table 1). This result therefore correlates well with previous findings that the type 2 diabetic group have a greater BMI.

Chromium is an essential trace element. Chromium deficiency and its relationship with high blood glucose levels has been documented[2]. Chromium acts by regulating or potentiating the action of insulin[7]. It is thought that chromium increases the number of insulin receptors and therefore increases insulin binding to cells. Anderson [9] suggested that the recommended daily intake of chromium for adults should be between $50-200 \mu \mathrm{g}$. Chromium, as previously mentioned, can be obtained from a wide variety of food products such as brewer's yeast, nuts and milk. Many studies have shown that it is difficult to obtain the minimum 50 $\mu \mathrm{g}$ from diet alone [10,11]. Supplemental chromium has been shown previously to improve glucose tolerance and circulating levels of insulin and cholesterol, although other studies showed that there was no change[9]. It is thought that this may reflect the large number of factors involved in the regulation of chromium metabolism such as genetics, nutrition, stress and underlying level of glucose tolerance [9].

The dietary intakes of the two groups of women in this study were surprisingly similar. The main differences were that there were fewer diabetics who reportedly ate cereals, chocolate, cream and milk and who drank alcohol. A greater proportion of the diabetics ate fruit. This may result from the dietary advice that the diabetics receive as part of their treatment plan.

It was found, using ICPMS analytic technology, that there was no significant difference in chromium levels between the two groups (table 5). In fact, the diabetic group recorded a slightly higher mean level of chromium. There was a wide range of measured chromium levels in both groups, and the lowest chromium level, was recorded in the diabetic group $(0.019 \mathrm{Vs} 0.050 \mu \mathrm{g} / \mathrm{g})$. This may be because, as previously mentioned, the dietary intake was very similar for the two groups. During the process of analysis, 2 control samples were lost due to accidental contamination, the results shown are therefore based on the results for 28 control samples.
These results are very similar to earlier findings by Rabinowitz et al in 1980 [6], who investigated chromium levels in hair samples of 46 diabetic men and compared them to levels of 20 agematched males. The study, based in Los Angeles, found that the differences between the mean levels of chromium between the two groups were not significant. The study also found its lowest recorded chromium levels were amongst the diabetics. Kazi et al in 1999, found significantly lower levels of chromium in a group of 25 diabetics, compared to age-matched controls [7]. The study was based on a population in Pakistan. Neither of these previous studies reported use of hair care products or compared the dietary intake of the two groups. A recent study of trace elements in the blood of 53 diabetics found that diabetics had lower levels of chromium, as well as iron, manganese and selenium but had increased levels of vanadium [12]. These results may show shortterm levels of the trace elements, rather then the chronic state that hair analysis reflects.

In summary, comparisons of chromium levels in the hair of people with type 2 diabetes and controls, in Caucasian females in a north England population, show a wide variation in levels. There was no significant difference in levels of chromium between the groups. To validate these findings it may be necessary to analyse a sample from a different population. This study also found that there were significantly less numbers of the diabetic group eating chocolate, cream, fruit, milk and alcohol. This reflects the dietary advice given to diabetic patients.

In conclusion the chromium status of type 2 diabetic women was not significantly different from a control group of women. Further work is necessary to precisely explore the relation between chromium and type 2 diabetes, if such a relationship exists.

\section{References}

[1]. Jeejebhoy K, Chu R, Marliss E, et al: Chromium deficiency, glucose tolerance, and neuropathy reversed by chromium supplementation, in a patient receiving long-term total parenteral nutrition. Am J Clin Nutr. 1977; 30:531-538.

[2]. Anderson RA. Chromium in the prevention and control of diabetes. Diabetes and Metabolism. 2000. 26(1):22-7.

[3]. Food Sources of Essential Minerals and Trace Elements. Institute of Food Research. Http://www.ifr.bbsrc.ac.uk.

[4]. Knight R, Haswell S, Lindow SW, Batty J Determination of mercury in hair by coupled CVAA-ICPMS. J Anal AT Spectrom 1999; 14:127-129

[5]. Davies S, McLaren Howard J, Hunnisett A. Age-related decreases in chromium levels in 51,665 hair, sweat, and serum samples from 40,872 patients - implications for the prevention of cardiovascular disease and type II diabetes. Metabolism: Clinical and experimental. 1997. 46(5):469-73.

[6]. Rabinowitz MB. Levin SR. Gonick HC. Comparisons of chromium status in diabetic and normal men. Metabolism: Clinical and experiemental.1980: 29(4):355-64

[7]. Kazi S, Ali SS, Kazi TG et al. Chromium: its role in diabetes and concentration in human scalp hair. American Clinical Laboratory 1999. 18(7):8.

[8]. Anderson RA, Polansky MM, Bryden NA et al. Effects of supplemental chromium on patients with symptoms of reactive hypoglycaemia. Metabolism 1987 36:351-355.

[9]. Anderson RA. Chromium, glucose tolerance and diabetes. Am J Clin Nutr.1998 17(6):548-55.

[10]. Anderson RA, Kozlovsky AS. Dietary intake, absorption and excretion of subjects consuming self-selected diets. Am J Clin Nutr 1985. 41:1177-1183.

[11]. Anderson RA, Bryden NA, Polansky MM. Dietary chromium intake - freely chosen diets, institutional diets and individual foods. Biol Trace Elem Res 42:454-461.

[12]. Ekmekcioglu C, Prohaska C, Pomazal et al. Concentrations of seven trace elements in different haematological matrices in patients with type 2 diabetes as compared to healthy controls. Biol Trace Elem Res, 2001. 79(3): 205-19 